\title{
A dinâmica e a influência das redes sociais para o sucesso empreendedor
}

\section{The dynamics and influence of social networks for entrepreneurial success}

\author{
VICTOR SILVA CORREA \\ Doutor em Administração pela PUC-MG \\ GLAUCIA MARIA VASCONCELLOS VALE \\ Professora Adjunta do Mestrado e Doutorado/ PUC Minas
}

\section{RESUMO}

Este artigo, resultado de reflexão teórica e de pesquisa empírica, procura investigar como funcionaram e como evoluíram as redes sociais de empreendedores provenientes de camadas de menor renda, que conseguiram, com o tempo, se projetar no mundo empresarial. Ao fazer isso, explora, por meio de pesquisa qualitativa comparativa associada aos recursos derivados da sociometria longitudinal, a história de dois empreendedores oriundos de camadas socioeconômicas mais vulneráveis. O referencial teórico ressaltou o processo empreendedor sob duas principais perspectivas. A primeira enfatizou os temas das redes sociais e do embeddedness, nos quais o empreendedor pode ser compreendido como ator condicionado e influenciado pela sua estrutura social. A segunda, por sua vez, destacou uma reflexão sobre as características pessoais, capazes de distinguir o empreendedor bem-sucedido dos demais. Os resultados sinalizam a relevância e o pioneirismo do estudo e sugerem ser o desenvolvimento dos empreendedores o resultado de uma combinação positiva entre suas características pessoais - entre as quais se inclui a capacidade de inovação - e as oportunidades presentes nas redes sociais e empresariais, capazes de evoluir com o tempo.

Palavras-chave: Empreendedorismo; redes sociais; baixa renda. 


\section{Abstract}

This article is the result of theoretical reflection and empirical research. It seeks to investigate how the social networks of entrepreneurs from lower income strata have been able to function over time in the business world. In doing so, he explores, through a comparative qualitative research associated with resources derived from longitudinal sociometry, the history of two entrepreneurs from the most vulnerable socioeconomic strata. The theoretical reference emphasized the entrepreneurial process under two main perspectives. The first emphasized the themes of social networks and embeddedness, in which the entrepreneur can be understood as a conditioned actor and influenced by his social structure. The second, in turn, highlighted a reflection on the personal characteristics, capable of distinguishing the successful entrepreneur from the others. The results signal the relevance and pioneering of the study. They suggest that the development of entrepreneurs is the result of a positive combination of their personal characteristics including innovation capacity - and the opportunities present in social and business networks that can evolve over time.

Keywords: Entrepreneurship; social networks; low income.

\section{INTRODUÇÃo}

A população brasileira é considerada uma das mais empreendedoras do mundo. Segundo dados do Global Entrepreneurship Monitor (GEM) (FELIX et al., 2010), o país ocupava a sexta posição em um conjunto formado por 22 nações com níveis comparáveis de desenvolvimento econômico, além do $14^{\mathrm{o}}$ lugar em um conjunto composto pelos 54 países pesquisados. No Brasil, a Taxa de Empreendedorismo em Estágio Inicial (TEA) é de 15,32\%, ou seja, a cada 100 cidadãos, 15 realizam alguma atividade empreendedora (GEM, 2010).

Entretanto, o país é caracterizado, ainda, por altas taxas de desigualdade socioeconômica. Mais de $88 \%$ da população brasileira - cerca de 167 milhões de pessoas - sobrevive com até três salários mínimos (IBGE, 2010). Ao mesmo tempo, 67,13\% pertence às classes C, D ou E, com renda familiar inferior a $\mathrm{R} \$ 1.319,00$ (http://www. abep.org/criterio-brasil, 2011).

Nesse segmento, o empreendedorismo ou o autoemprego se apresenta, muitas vezes, como opção ao desemprego ou ao trabalho 
precário. Os empreendedores, nesse contexto, podem não possuir alguns recursos considerados importantes para o sucesso empresarial, como informações adequadas, recursos financeiros e habilidades gerenciais, eventualmente imersos (embedded) nas redes sociais (AUDRETSCH et al., 2002; STOREY, 1994; UHLANER; THURIK, 2007; GRANOVETTER, 1983, 1985).

Além disso, pessoas oriundas de segmentos sociais de baixa renda não teriam, teoricamente, condições de usufruir uma variedade de contatos e de relacionamentos, que, por possuírem recursos das mais diversas naturezas, permitiriam alavancar os empreendimentos. Pelo contrário, os relacionamentos dos empreendedores podem se encontrar em um contexto mais limitado, constituídos, em geral, por laços fortes, que seriam inibidores ou pouco propensos a sustentar atividades empreendedoras. Mas, o que se observa, na prática empresarial, é que algumas dessas pessoas conseguem superar suas limitações e se projetam como empreendedor. O presente artigo se propõe a investigar essa dinâmica.

$\mathrm{O}$ trabalho se encontra dividido em três partes. A primeira apresenta o referencial teórico, que foca os temas das redes sociais e do embeddedness. Soma-se a isso uma reflexão sobre características pessoais, capazes de distinguir o empreendedor bem-sucedido dos demais. Observa-se que a associação entre essas duas abordagens distintas, que mostram, por um lado, o processo empreendedor no contexto das redes sociais e, por outro, o empreendedor de maneira mais atomizada, baseado em atributos pessoais, como aqui destacado, produz resultados altamente positivos. As vantagens e os reflexos dessa associação têm sido, nos últimos anos, enfatizados por alguns autores (STARR; MACMILLAN, 1991; SEXTON; SMILOR, 1997). A segunda parte traz a metodologia de pesquisa - com utilização dos recursos derivados da sociometria longitudinal - e os resultados da investigação. Finalmente, a conclusão resgata e sintetiza as principais descobertas, avalia os seus impactos e as suas contribuições.

Além de avançar nessas reflexões, o artigo oferece outras contribuições. No campo teórico, espera-se contribuir para a literatura sobre empreendedorismo, derivado da melhor compreensão sobre a importância e sobre a participação das redes sociais e das características pessoais para o desenvolvimento de empreendedo- 
res oriundos de camadas sociais menos favorecidas. No contexto metodológico, a expectativa é colaborar ao reforçar a possibilidade do uso dos recursos da sociometria longitudinal para as pesquisas da área.

\section{A BASE TEÓRICA}

A visão do empreendedor como um agente de articulação e de intermediação de redes não mereceu uma reflexão mais estruturada até estudos recentes. Foi a partir dos trabalhos de Leibenstein (1968), aperfeiçoados por Granovetter (1973, 1985, 1992) e Burt (2000), que o tema ganhou importantes contribuições (VALE; OLIVEIRA, 2010). Nas extensões de interesse deste artigo, as proposições fundamentais sobre redes sociais e embeddedness se originam dos trabalhados de Granovetter (1973, 1983, 1985).

Embora o interesse inicial de Granovetter não fosse, exatamente, a temática do empreendedorismo $(1973,1985)$, suas reflexões permitiram amplo tratamento do tema e acabaram por abarcá-lo posteriormente (GRANOVETTER, 2003). Insere-se aí a preocupação com a intensidade dos "laços sociais" que, para o autor, podem ser de duas categorias: fortes e fracos. Os primeiros são formados por ocasiões em que os contatos com a díade são pouco frequentes e, geralmente, de curta duração (GRANOVETTER, 1983). Sugerem contatos mais superficiais, que são estabelecidos entre diferentes redes. Os laços fracos fornecem aos empreendedores acesso a recursos e a informações que ultrapassam aqueles disponíveis no próprio círculo social (GRANOVETTER, 1983; HITE, 2005).

Já os laços fortes são constituídos por contatos intensos e frequentes (GRANOVETTER, 1973, 1983). Quanto mais fortes forem os vínculos que interligarem dois ou mais indivíduos, mais parecidos estes serão uns com os outros. Assim, esses laços sugerem a formação de redes sociais, que são conjuntos ou comunidades integradas e coesas (GRANOVETTER, 1973). Redes sociais mais densas são mais usuais entre participantes com algum tipo de contexto similar, como etnia, ideologia ou aspecto profissional (POWELL, 1990). Um exemplo é a família, que, dada a grande coesão e similaridade de seus membros, é entendida como uma rede formada por laços fortes. Nesse contexto, variáveis como tempo e frequência de contato, 
intensidade emocional, intimidade e reciprocidade podem influenciar a "força" dos laços entre as díades (GRANOVETTER, 1973).

Caracterizadas por possibilitar maior motivação e assistência aos membros de uma rede, as conexões fortes são mais facilmente disponíveis, fator que transforma o desempenho desse tipo de ligação único. Ao mesmo tempo, os vínculos fortes denotam a reprodução da mesma estrutura social, uma vez que se restringem às conexões de indivíduos com características semelhantes dentro de um mesmo grupo social (GRANOVETTER, 1983).

Nesse contexto, Granovetter (1973) defende a "força dos laços fracos". Os laços fortes, embora possibilitem o acesso mais facilitado aos recursos das redes, são inibidores ou pouco propensos a sustentar o empreendedorismo dos indivíduos, uma vez que não conseguem dotá-los de contatos que extrapolem seu próprio mundo de relações. Por outro lado, os laços fracos são capazes de integrar indivíduos em mundos e em contextos distantes. Essas conexões com diversas redes possibilitam a difusão e a circulação de diferentes e importantes informações e oportunidades do mundo empresarial. Grupos empreendedores de sucesso, comparados com outros, frequentemente têm uma rede de relacionamentos mais ampla com indivíduos situados em outras localizações ou contextos sociais (VALE; OLIVEIRA, 2010). Ao analisar o problema de empreendedores oriundos de grupos de imigrantes em vários países, Granovetter (2003) destaca não apenas a importância dos laços fracos para a atividade empreendedora, mas passa a destacar também a presença de uma situação de acoplamento e desacoplamento do empreendedor, ou seja, a dinâmica entre os laços fortes e os fracos (2003).

Em uma rede social há mais laços fracos que fortes, e a maioria dos laços fracos transmite informações com pequeno grau de importância aos empreendedores. Porém, a relevância dos laços fracos, na perspectiva de Granovetter (1973, 1983, 2005, 2005a), se endossa na medida em que esse tipo de conexão é mais provável de transmitir informações e oportunidades únicas em comparação com os laços fortes (GRANOVETTER, 2005, 2005a).

Posteriormente, Granovetter (1985, 2005, 2005a) avança em suas reflexões sobre o papel e sobre a força dos laços sociais e, pautado na vertente da nova sociologia econômica, elabora o conceito de 
embeddedness (GRANOVETTER, 1985; PEIXOTO; MARQUES, 2003; VALE, 2006). Para Granovetter (2007, p. 3), “os comportamentos e as instituições a serem analisados são tão compelidos pelas relações sociais que interpretá-los como sendo independentes representa um grave mal-entendido". Na visão do autor, as relações econômicas estão imersas (embedded) nas relações sociais, da mesma forma que as relações sociais estão enraizadas nas interações econômicas. Assim, de igual maneira em que os aspectos mercantis influenciam e extravasam rumo às relações sociais, as interações de ordem social repercutem nas trocas econômicas. Há uma interpenetração de ações econômicas e não econômicas (GRANOVETTER, 2005).

Dessa forma, na perspectiva de Granovetter $(1985,2005)$, não é incomum surgir uma relação de amizade e de confiança entre díades que eram, em um momento inicial, pautados apenas por relações comerciais. De forma análoga, as relações de amizade podem evoluir e se tornar relacionamentos pautados também por características comerciais (GRANOVETTER, 1985, 2005, 2005a; HITE, 2005; LARSON; STAR, 1993; VALE, 2008).

Insere-se nesta reflexão a análise da evolução das redes empreendedoras. Inúmeros autores já salientaram essa matéria (LARSON; STAR, 1993; HITE, 2005; JOHANNISSON, 1998; POWELL; GRODAL, 2006; VASCONCELOS, 2007; HITE, 2003; LECHNER; DOWLING, 2003). Segundo Greve e Salaff (2003, p. 14), diversos "pesquisadores salientam sobre a importância dos laços fracos para ampliar as informações, porque empreendedores que continuam a depender dos membros da família limitam seus círculos". Para Hite (2005), as redes empreendedoras não são estáticas, se desenvolvem com o tempo. Argumento similar defendem Powell e Grodal (2006, p. 63), segundo os quais as redes evoluem ao longo do processo empresarial, razão por que, dessa forma, é "improvável assumir que elas permaneçam fixas".

As mudanças ao longo do tempo compreendem não apenas os recursos que as redes provêm, como também a natureza de sua composição, como as especificidades dos laços (JOHANNISSON, 1998). No começo dos negócios, por exemplo, os empreendedores acessam laços fortes para obter recursos das mais diversas naturezas, como informações, suporte financeiro e outros. Com a evolu- 
ção do empreendimento, os indivíduos, com o objetivo de buscar novos parceiros e recursos, se veem obrigados a procurar conexões e contatos adicionais - geralmente laços fracos (GREVE; SALAFF, 2003; LARSON; STAR, 1993; HITE, 2005; SHAPERO; SOKOL, 1982).

Hite (2005) defende que os empreendedores podem estar imersos em diferentes tipos de redes, as quais podem ser formadas por relacionamentos de duas categorias: pessoais ou econômicas. Porém, os laços inicialmente pessoais podem evoluir para redes de interações econômicas, da mesma forma que os relacionamentos exclusivamente econômicos podem progredir para interações de confiança e de amizade, como já destacado por Granovetter (1985) com o conceito de embeddedness.

Essa evolução dos laços é possibilitada pelo o que Hite (2005) cunhou de "Processo de Alavancagem Social", que é a utilização de atributos de certo componente social como uma "alavanca" em direção à junção de um segundo componente social (HITE, 2005). Imagine uma situação hipotética de um empreendedor imerso apenas em relacionamentos pessoais associados ao conceito de laços fortes. Essas relações são caracterizadas por diversos atributos, como conhecimento pessoal e sociabilidade. A interação entre os atributos proporciona o aumento da probabilidade de se encontrarem novas pessoas e, com isso, promover a "alavancagem" para novas relações pessoais e econômicas.

Segundo Lechner e Dowling (2003), a sobrevivência das empresas está diretamente relacionada com a capacidade que os indivíduos possuem de manter e de estender a rede de relacionamentos. Essa expansão do conjunto de contatos, possibilitada pelo processo de alavancagem social, permanece desconhecida para o contexto dos empreendedores provenientes de baixa renda, dotados, inicialmente, de uma base de contato mais restrita.

Observa-se que tais perspectivas teóricas enfocam o empreendedor associado a determinado contexto social, de natureza relacional. Outra perspectiva, também de interesse no presente trabalho, preocupa-se em identificar as características pessoais capazes de distinguir o empreendedor dos demais. Inserem-se, nesse contexto, duas argumentações emblemáticas: a primeira, de Schumpeter (1982), e a segunda, de McClelland (1972). Para Schumpeter (1982), 
os empreendedores são os agentes sociais capazes de inovar. Salienta o autor que "ao empreendimento de novas combinações denominamos empresa, e aos indivíduos cuja função é realizá-las, empreendedores" (SCHUMPETER, 1959, p. 105). E complementa que “[...] qualquer que seja o tipo enfocado, alguém só pode ser considerado um empreendedor quando efetivamente levar a cabo novas combinações e inovações" (SCHUMPETER, 1982, p. 56). O empreendedor de Schumpeter é um indivíduo dotado de certo grau de insatisfação social e, como tal, capaz de mudar a sua realidade.

Para McClelland (1972), mais que recompensas financeiras, é a necessidade de realização pessoal que motiva os indivíduos a buscarem o envolvimento nas atividades empreendedoras. Isso porque pessoas motivadas pela necessidade de realização canalizam energia para a melhoria e para o constante progresso de seus empreendimentos. Algumas qualidades e peculiaridades como audácia, engenhosidade, liderança, persistência, determinação e coragem para assumir riscos moderados, entre outras, foram atribuídas ao empreendedor por estudos dessa linha de pensamento.

Em ambas as reflexões se observa uma ênfase na figura do empreendedor como um ator atomizado e individualizado. Tais proposições levam até mesmo à visão de um "grande homem", dotado de certas características que o tornam peculiar dentre os demais, remetendo-o a um paradigma de "self-made-man" (SOUZA NETO, 2008). De forma geral, a concepção tradicional do empreendedor traz no seu bojo uma visão que "sedimenta uma imagem romântica e mitificada de um indivíduo portador de qualidades e habilidades excepcionais" (COLBARI, 2007, p. 1).

Outras reflexões, contudo, vêm se referindo à necessidade de associar, por um lado, a abordagem do empreendedor inserido em dado contexto social e, por outro, a perspectiva que o distingue como um ator social detentor de certos atributos pessoais diferenciados. Inserem-se nessa perspectiva os trabalhos de Starr e MacMillan (1991) e Sexton e Smilor (1997). Sexton e Smilor (1997) salientam a negligência de algumas abordagens teóricas que focalizam os empreendedores somente como tomadores autônomos de decisões, desconsiderando, portanto, a linha de raciocínio que incorpora também o empreendedor em dado contexto social, canalizado ou 
constrangido pela natureza e pela posição em determinada rede social. Starr e MacMillan (1991) complementam essa reflexão ao afirmar que os empreendedores devem alavancar recursos para seus empreendimentos. Para os autores, os empreendedores não atuam em um mercado neoclássico anônimo e perfeitamente competitivo; em vez disso, operam em um contexto imerso (embedded) em um sistema concreto e dinâmico de relações sociais (STARR; MACMILLAN, 1991).

De fato, a associação entre, por um lado, a abordagem atomizada e, por outro, a perspectiva relacional, parece trazer benefícios para os casos analisados, como será mostrado a seguir.

\section{Metodologia e resultados de pesquisa}

A estratégia de pesquisa utilizada foi qualitativa exploratória, e o estudo de caso, o método empregado. A investigação, baseada na análise longitudinal de dois casos, utilizou duas fontes de evidências - entrevistas e documentação -, por meio da triangulação de dados, tática utilizada para elevar a validade do constructo (BAUER; GASKELL; 2002; GREENWOOD, 1973; YIN, 2007, GODOY, 1995).

A estratégia analítica geral se baseou em proposições teóricas em que o referencial atuou como um guia para o exame dos casos investigados. As técnicas analíticas específicas foram as análises intracaso e as comparações intercasos. Utilizou-se a sociometria, por meio dos sociogramas, ou seja, "diagramas de redes que permitem a visualização da estrutura que está sendo estudada" (MARTELETO; SILVA, 2004, p. 42). O sociograma é o mais importante instrumento originado da sociometria e atua como base para demonstrar e visualizar a estrutura das redes sociais e empresariais (BATAGELJ; MRVAR; NOOY, 2005).

Os dois casos pesquisados foram o Restaurante Matusalém e Souza \& Souza Construção e Reforma. O primeiro, Matusalém Gonzaga, casado, 50 anos, é um dos importantes chefs brasileiros, reconhecido internacionalmente por jornais e por periódicos pelo seu talento nas culinárias italiana, mexicana e, sobretudo, brasileira, com especialidades nas cozinhas mineira e baiana. Atualmente, é o sócio-fundador do Restaurante Matusalém, com sede em Belo Hori- 
zonte. A participação societária é dividida em 50\% para Matusalém, $25 \%$ para Eudes e $25 \%$ para Oséas, irmãos do empreendedor.

Com mais de 50 empregados diretos e faturamento médio anual bruto de 960 mil reais, o restaurante é atualmente uma das alternativas de comida mineira e baiana de Belo Horizonte. O espaço disponibiliza mais de 190 opções, entre aperitivos, caldos, entradas, porções, sobremesas e bebidas. Com o objetivo de promover o espaço, Matusalém e os irmãos realizam eventos gastronômicos regionais, nacionais e internacionais que contribuem para a abertura de mercados e para a construção de novas redes de relacionamentos. Além disso, integram a Associação Brasileira de Bares e Restaurantes de Minas Gerais (Abrasel), na qual Matusalém atua como líder e como gestor da Câmara Setorial da Pampulha, que congrega outros dez estabelecimentos da região.

Mas a história de Matusalém nem sempre foi marcada pela liderança ou pelo reconhecimento no ramo gastronômico. Até obter sucesso no mercado, trabalhou ainda criança para ajudar no sustento da família, que morava em uma cabana simples na periferia de Contagem, Região Metropolitana de Belo Horizonte. Quando adolescente, se mudou para Rondônia, onde, por necessidade, aprendeu a cozinhar jacarés, caçados com a ajuda de seringueiros locais, além de comidas com mandiocas, mamão e folhas retiradas das matas e das plantações locais. Antes de abrir seu empreendimento, atuou ainda como entregador de alimentos da Coziminas, ajudante geral do Hotel Real Palace, lavador de panelas no Hotel Brasilton e cozinheiro, entre outras atividades.

Para conquistar sucesso no ramo gastronômico, Matusalém contou com a influência e com a contribuição de diversos contatos construídos ao longo da vida. A Figura 1 apresenta, por meio de sociograma longitudinal, os principais relacionamentos estabelecidos por Matusalém entre 1970, período em que conseguiu o primeiro trabalho, e 2010. 
Figura 1: Sociograma longitudinal representativo dos relacionamentos criados por Matusalém ao longo da trajetória empreendedora

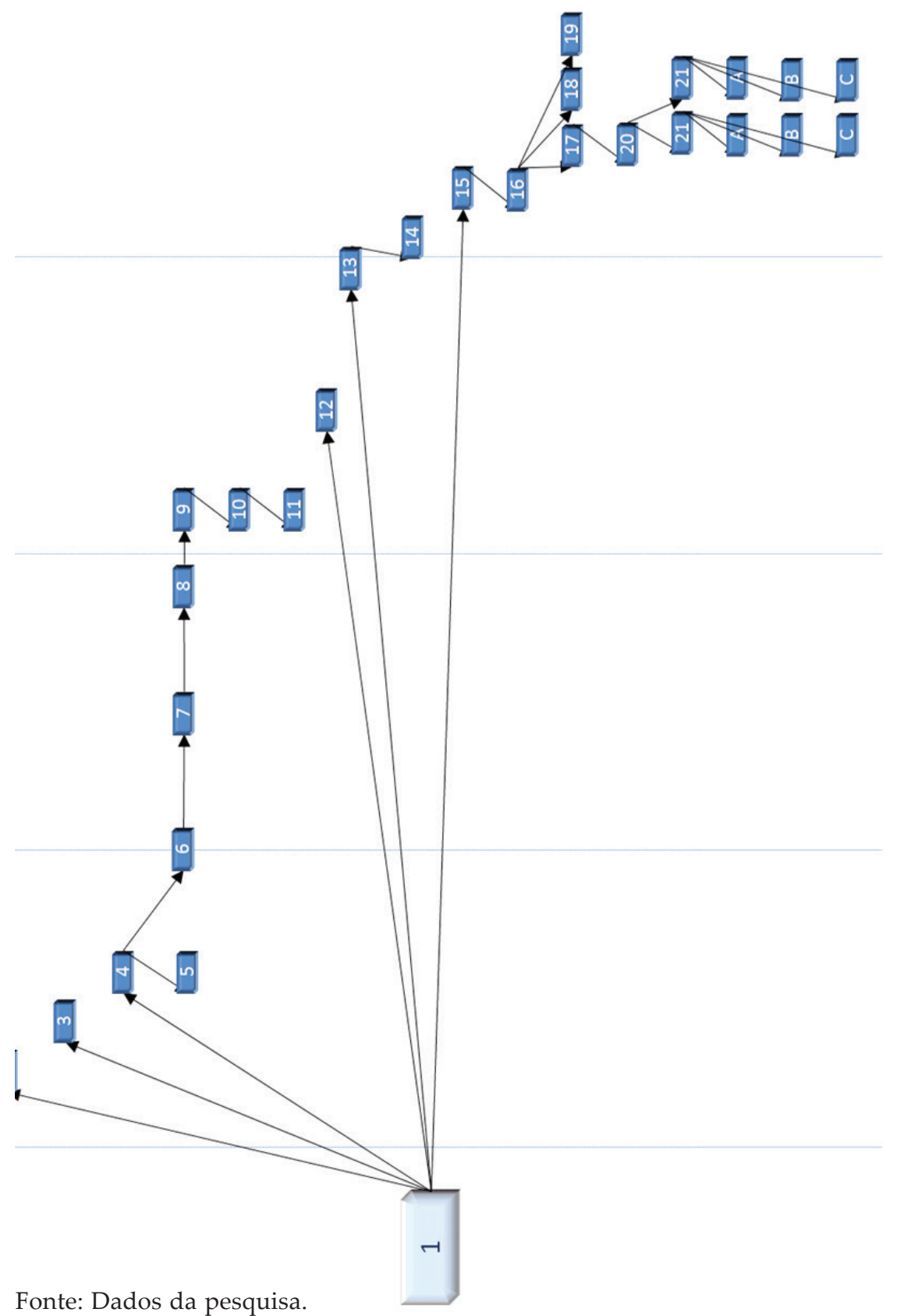


A Figura 1 apresenta as principais díades construídas por Matusalém, destacando, por um lado, o período no qual o relacionamento foi estabelecido e, por outro, a formação das redes sociais. Destacam-se a atuação e a contribuição de quatro importantes contatos: Oséas (alter 4), Dada Bahia (alter 13), Iraildes (alter 16) e Saulo Fernandes (alter 20). Oséas, caracterizado por laço forte, indicou Matusalém para o Real Palace e para o Brasilton, em 1976 e início da década de 1980, respectivamente. Os hotéis, que foram os dois primeiros trabalhos de Matusalém após o retorno de Rondônia, se apresentaram também como os locais nos quais Matusalém iniciou efetivamente suas atividades e seus aprendizados no ramo gastronômico. A indicação de Oséas possibilitou, além disso, a construção de novas e importantes conexões para Matusalém, tais como Flávio (alter 7), Roberto (alter 8) e Luis (alter 9), que o convidaram para novos trabalhos e empreendimentos no contexto gastronômico, possibilitando, com isso, o desenvolvimento de Matusalém no setor.

Dada Bahia, que conheceu Matusalém em esporádicos eventos gastronômicos, caracterizando-se, dessa forma, como um relacionamento formado, sobretudo, por laço fraco, convidou-o, em 2002, para administrar seu restaurante em Salvador, reflexo da experiência obtida por ele em trabalhos passados. Além disso, apresentou Leonel (alter 14), que vendeu o espaço utilizado por Matusalém para criar, no mesmo ano, em Salvador, o estabelecimento que levou o próprio nome.

Já Iraildes, então gerente do Sebrae na Bahia, contribuiu, por meio de consultoria e de formação educacional, para os processos de abertura e de crescimento do Restaurante Matusalém. Ademais, Iraildes, contato inicialmente pouco frequente, apresentou o empreendedor a diversas díades, que possibilitaram a expansão de sua rede de relacionamentos, contribuindo, igualmente, para o desenvolvimento de seu empreendimento. Destacam-se, entre os contatos apresentados, a influência e a repercussão dos gerentes dos Hotéis Pestana (alter 17), que, ao conhecerem Matusalém nos cursos do Sebrae, convidaram-no a promover um jantar em um cassino do grupo. No evento, realizado em Portugal, conheceu o cantor Saulo Fernandes, que indicou o restaurante baiano à comunidade artística nacional, projetando o empreendimento para novos públicos. 
Observam-se, associadas à formação e à construção de novos relacionamentos, a influência e a contribuição que os atributos pessoais de Matusalém - entre os quais se inclui a capacidade de inovação -, tiveram para o sucesso do empreendedor no contexto mercadológico. A manifestação de tais características, exemplificadas, entre outras, pelo esforço, determinação e coragem, pode ser observada, por exemplo, em dois momentos. O primeiro se deu quando Matusalém comprou o espaço em Salvador, mesmo sem recursos financeiros suficientes; e o segundo, quando abriu o restaurante a despeito da condição aparentemente desfavorável na época, como, por exemplo, os poucos relacionamentos estabelecidos no norte do país, resultado, em parte, pelo curto tempo de moradia do empreendedor na Bahia.

Ademais, Matusalém pode ser interpretado, também, como um empreendedor que promove inovações, exemplificadas, sobretudo, em três principais situações. A primeira se refere às diferentes opções de menus do restaurante, que servem, atualmente, mais de 190 produtos, muitos deles frutos das experimentações passadas do empreendedor. A segunda alude à disposição de Matusalém em abrir novos mercados, observada nos momentos em que criou e administrou diversos restaurantes. Finalmente, a terceira acena para a intenção do Matusalém de criar, o mais breve possível, novos estabelecimentos em Belo Horizonte.

O segundo caso investigado, José Souza da Conceição, casado, 47 anos, é empreendedor e dono da Souza \& Souza Construção e Reforma Ltda., empresa especializada em serviços de reforma geral que envolvem profissionais como pedreiros, bombeiros, pintores, marceneiros e eletricistas, entre outros. Criada em 1997, possui, atualmente, oito empregados fixos, além de vários prestadores de serviços autônomos, o que lhe permite cobrir um amplo escopo de necessidade do mercado associado à construção civil. Sua carteira de clientes é composta por mais de 400 empresas e pessoas físicas, entre condomínios, prédios comerciais e residências.

Entretanto, a trajetória de José Souza nem sempre foi marcada pelo sucesso empresarial. Natural de Nanuque, nordeste de Minas Gerais, viveu até os 16 anos na pequena roça dos pais, local em que trabalhava no plantio e na colheita de alimentos. A falta de emprego 
na região, aliada à vontade de tentar a vida na capital, como fizeram o irmão mais velho e os pais anos antes, motivaram José Souza, em 1979, a se mudar para o bairro União, em Belo Horizonte. Desde sua chegada à capital mineira, com 17 anos e nível fundamental incompleto ( $5^{-}$ano), trabalhou como servente de pedreiro, auxiliar de pintor e outros e contou, inicialmente, com a colaboração dos relacionamentos alavancados nesses serviços para se projetar no contexto empreendedor.

A Figura 2 apresenta, por meio de sociograma longitudinal, os principais contatos estabelecidos por José Souza entre 1970 e 2010.

A Figura 2 apresenta os principais relacionamentos estabelecidos por José Souza. Demonstra, ademais, a formação das redes de contatos construídas ao longo de sua trajetória. Destacam-se, nesse contexto, a influência e a importância, sobretudo, de Vandôr (alter 5), Tereza (alter 7) e Lina (alter 22). A principal contribuição de Vandôr, primeiro empregador de José Souza em Belo Horizonte, foi apresentá-lo à Tereza, que se tornou uma das mais importantes clientes do empreendedor, além de ter indicado José Souza para diversos outros contatos de sua rede de relações. Ou seja, por meio da influência e das indicações de Vandôr e, principalmente, de Tereza, José Souza conseguiu os primeiros clientes, que possibilitaram sua projeção como empreendedor.

A contribuição de Lina, caracterizada, a exemplo das duas díades já destacadas, por laço fraco, foi apresentar José Souza a diversos moradores do condomínio em que morava. Esses novos relacionamentos possibilitaram, da mesma forma que os benefícios derivados das indicações de Vandôr e de Tereza, a expansão e a ampliação do volume de clientes e de negócios estabelecidos pelo empreendedor. Dessa maneira, apesar de não possuir contatos em Belo Horizonte quando de sua chegada à cidade, José Souza construiu diversos relacionamentos por meio das indicações de profissionais que conheceu nos primeiros trabalhos em que atuou como auxiliar de pedreiro. Esses contatos contribuíram, por um lado, para o acesso a diversos novos clientes e, por outro, para a consolidação como empreendedor, treze anos antes de oficializar o próprio negócio, em 1997.

É possível observar, associado aos benefícios obtidos por meio dos relacionamentos criados, como as características pessoais de José 
Figura 2: Sociograma longitudinal representativo dos relacionamentos criados por José Souza ao longo da trajetória empreendedora
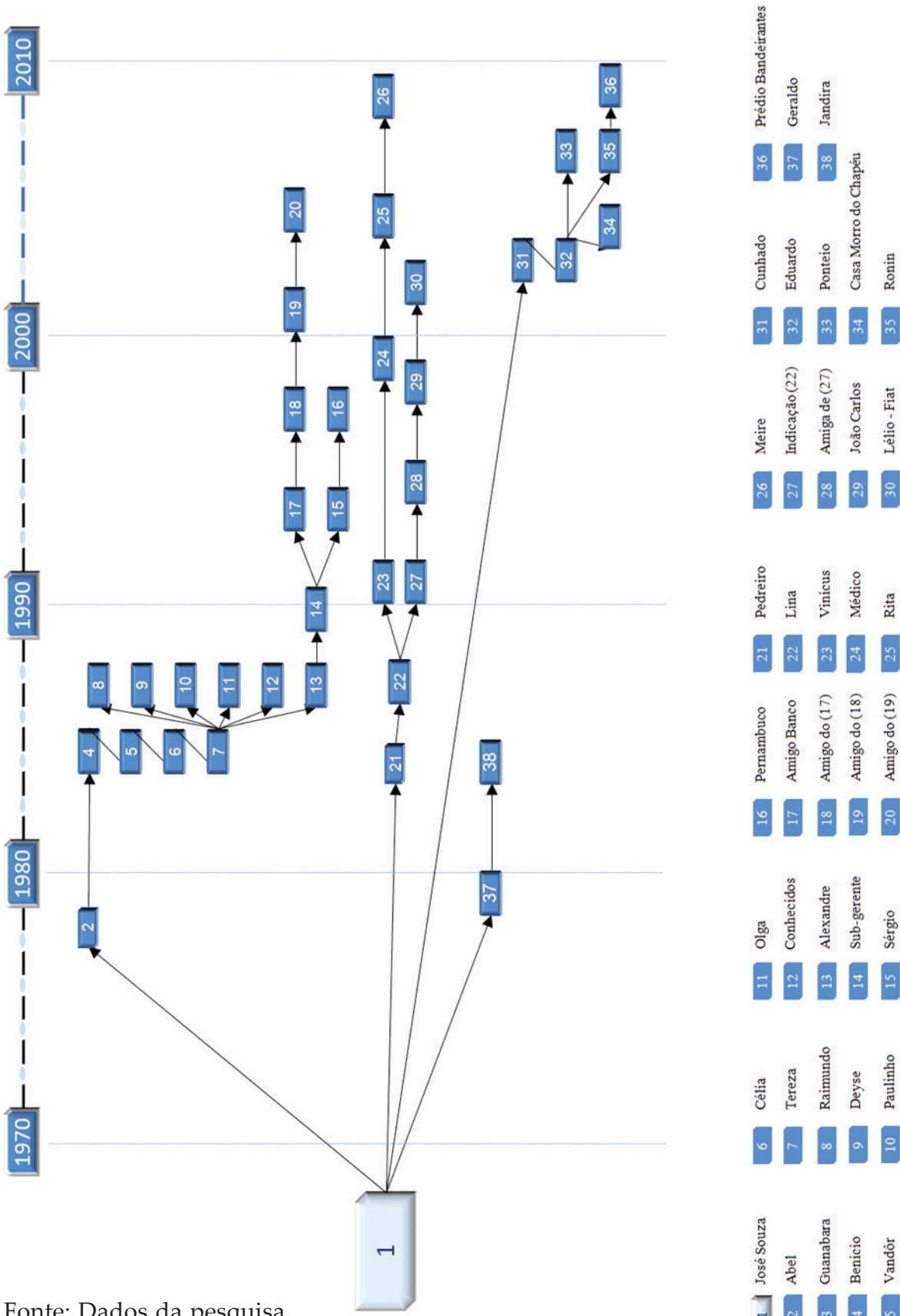

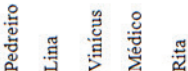

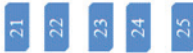

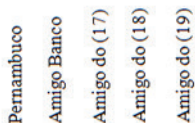

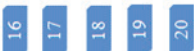

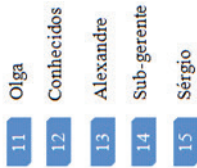

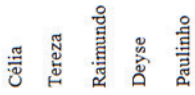

$\circ \infty \infty$ a $\infty$

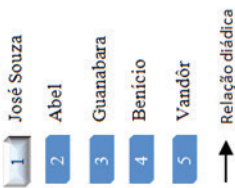


Souza - como esforço, comprometimento, determinação e capacidade de inovação - influenciaram e contribuíram para o desempenho e o sucesso do empreendedor. A manifestação dessas qualidades pode ser observada em três importantes momentos. O primeiro ocorreu quando José Souza mudou de cidade em busca de trabalho e renda; o segundo, quando atuava em diferentes obras com o objetivo de, por um lado, manter-se no emprego fixo e, por outro, construir novos relacionamentos, ampliando as próprias possibilidades de crescimento no mercado; e, finalmente, quando passou a disponibilizar serviços customizados aos clientes, demonstrando, na época, capacidade de iniciativa e, sobretudo, de inovação no conceito e na aplicabilidade do negócio. Ou seja, o empreendedor atende a um grande volume e variedade de clientes, a despeito de possuir uma estrutura funcional proporcionalmente enxuta, com oito profissionais.

\section{CONSIDERAÇõES FINAIS}

Os resultados obtidos permitem tecer algumas considerações sobre o fenômeno investigado. Ao se analisarem os casos, é possível observar que, apesar das limitações iniciais relacionadas às suas redes de relacionamentos, ambos os empreendedores obtiveram acesso, em geral, a certos laços fracos, que foram fundamentais para, a partir daí, ajudar, por um lado, a alavancar seus empreendimentos e, por outro, a promover mudanças positivas nas organizações.

$\mathrm{O}$ que se nota nesses momentos de alterações e de transições, em geral, é a capacidade de os empreendedores aproveitarem as oportunidades, associadas, sobretudo, aos relacionamentos estabelecidos. É possível perceber também a repercussão e a influência dos atributos pessoais: ambos os empreendedores investigados demonstraram, de maneiras distintas, capacidade de iniciativa, espírito de luta, vontade de prosperar, disposição para assumir riscos, perseverança e inovação, entre outros atributos essenciais a empreendedores bem-sucedidos.

Dessa forma, a análise desses casos possibilita mostrar a importância de tentativas de conciliar, por um lado, reflexões derivadas da teoria das redes sociais (GRANOVETTER, 1973; 1983; 1985; 2003, 2007) e, por outro, proposições sobre atributos pessoais (SCHUMPE- 
TER, 1982; MCCLELLAND, 1972) para o sucesso de empreendedores oriundos de camadas sociais menos favorecidas. Espera-se que os resultados aqui apresentados possam contribuir para ampliar o entendimento sobre a influência e a contribuição das redes sociais e das características pessoais para o sucesso dos empreendedores. Além disso, espera-se colaborar para melhor compreensão da realidade de empreendedores provenientes de camadas sociais vulneráveis.

Novas pesquisas, no entanto, devem ser realizadas com o propósito de ampliar o escopo de observações, seja no contexto de estudos de casos, seja no de pesquisas amostrais representativas de diferentes segmentos e realidades presentes no país.

\section{REFERÊNCIAS}

AUDRETSCH, D. B. et al. Entrepreneurship: determinants and policy in a European-US comparison. Boston: Kluwer Academic Publishers, 2002.

BATAGELJ, V.; MRVAR, A.; NOOY, W. Exploratory Social Network Analysis with Pajek. New York: Cambridge University Press, 2005. V. 27.

BAUER, M. W.; GASKELL, G. Pesquisa Qualitativa com texto, imagem e som: um manual prático. 2. ed. Petrópolis: Vozes, 2002.

BURT, R. S. The network structure of social capital. In: STAW, B. M.; SUTTON, R. I. Research in organizational behavior. New York: Elsevier Science Inc., 2000. Disponível em: <http://books.google.com.br/books?hl=pt-BR\&lr=\&id=WAEur1SSQdcC\&oi=fnd\&pg=PA345 $\& \mathrm{dq}=$ The+Network+Structure+of+Social+Capital\&ots=M76HA2VNmA\&sig=togHP8VSNQ Uxr-YngEGwMZGkh50\#v=onepage\&q=The\%20Network\%20Structure\%20of\%20Social\%20 Capital\&f=false>. Acesso em: 19 mar. 2009.

COLBARI, A. de L. A retórica do empreendedorismo e a formação para o trabalho na sociedade brasileira. Sinais, Vitória, v. 1, n. 1, p. 75-111, abr. 2007. Disponível em: <http://migre. me/NN8L>. Acesso em: 15 abr. 2009.

FELIX, J. C. et al. Relatório GEM - Global Entrepreneurship Monitor. London, UK: Babson Park, 2010.

GODOY, A. S. Pesquisa Qualitativa: tipos fundamentais. Revista de Administração de Empresas, São Paulo, v. 35, n. 3, p. 20-29, maio/jun. 1995.

GRANOVETTER, M. The strength of weak ties. American Journal of Sociology, v. 78, n. 6, p. $1360-1380,1973$.

. The strength of weak ties: a network theory revisited. Sociological Theory, v. 1, p. 201-233, 1983.

Economic action and social structure: the problem of

embeddedness. American Journal of Sociology, Chicago, v. 91, n. 3, p. 481-510, nov. 1985. 
. Problems of explanation in economic sociology. In: NOHRIA N.; ECCLES, R. G. (Org.). Networks and organizations: structure, form and action. Massachusetts: Harvard Business School, 1992. p. 25-56.

. Introduction à La Sociologie Économique des Entreprises et des Entrepreneurs. Terrains \& Travaux, v. 1, n. 4, p. 162-1666, 2003.

. The economic sociology of firms and entrepreneurs. In: PORTES, A. Sociology of immigration: essays on networks, ethnicity, and entrepreneurship. New York: Russell Sage Foundation, 2005, p. 128-165.

. The impact of social structure on economic outcomes. The Journal of Economic Perspectives, v. 19, n. 1, p. 33-50, 2005a.

. Ação econômica e estrutura social: o problema da imersão. RAE Eletrônica, v. 6, n. 1, jun. 2007.

GREENWOOD, E. Métodos principales de investigación social empírica. In: SJOBERG, G.; NETT, R. Metodología de la Investigación Social. Buenos Aires: Paidos, 1973. Cap. 6, p. 106-126.

GREVE, A; SALAFF, J. W. Social network and entrepreneurship. Entrepreneurship, Theory and Practice, v. 28, n. 1, p. 1-22, 2003.

HITE, J. M. Patterns of multidimensionality among embedded network ties: a typology of relational embeddedness in emerging entrepreneurial firms. Strategic Organization, London, v. 1, n. 1, p. 9-49, 2003.

. Evolutionary processes and paths of relationally embedded network ties in emerging entrepreneurial firms. Entrepreneurship Theory and Practice, v. 29, p. 113-143, jan. 2005.

IBGE - Instituto Brasileiro de Geografia e Estatística. 2010. Disponível em: <http://censo2010. ibge.gov.br/resultados.html>. Acesso em: 22 mai. 2017.

JOHANNISSON, B. Personal networks in emerging knowledge-based firms: spatial and functional patterns. Entrepreneurship and Regional Development, v. 10, n. 4, p. 297-312, out./dez. 1998.

LARSON, A.; STARR, J A. A network model of organization formation. Entrepreneurship Theory and Practice, Waco, v. 17, n. 2, p. 5-16, 1993.

LECHNER, C.; DOWLING, M. Firm networks: external relationships as sources for the growth and competitiveness of entrepreneurial firms. Entrepreneurship \& Regional Development, Regensburg, Germany, v. 15, p. 1-26, 2003.

LEIBENSTEIN, H. Entrepreneur and development. The American Economic Review, v. 58, n. 2, p. 72-84, May 1968.

MARTELETO, R. M.; SILVA, A. B. de O. Redes e capital social: o enfoque da informação para o desenvolvimento local. Ci. Inf., Brasília, v. 33, n. 3, p. 41-49, set./dez. 2004.

MCCLELLAND, D. C. A sociedade competitiva. Rio de Janeiro: Expressão e Cultura, 1972. PEIXOTO, J.; MARQUES, R. A sociologia econômica em Portugal. Sociologia, Problemas e Práticas, n. 42, p. 201-216, maio 2003.

POWELL, W. W.; GRODAL, S. Networks of innovators. In: FAGERBERG, J.; MOWERY, D. C.; NELSON, R. R. (Org.). The Oxford Handbook of Innovation. New York: Oxford University Press, USA, 2006, pp. 56-85. 
POWELL, W. W. Neither market nor hierarchy: network forms of organization. Research in Organizational Behavior, v. 12, p. 295-336, 1990.

SCHUMPETER, J. A. Teoria do desenvolvimento econômico. Rio de Janeiro: Fundo de Cultura, 1959.

Teoria do desenvolvimento econômico: uma investigação sobre lucros, capital, crédito, juro e o ciclo econômico. São Paulo: Abril Cultural, 1982.

SEXTON, D. L.; SMILOR, R. A. Y. (Ed.). Entrepreneurship 2000. Chicago, Ill.: Upstart Publishing, 1997.

SHAPERO, A.; SOKOL, L. The social dimensions of entrepreneurship. In: KENT, C.; SEXTON, D.; VESPER, K. (Org.). Encyclopedia of Entrepreneurship, Englewood Cliffs. New Jersey: Prentice-Hall, 1982. p. 72-90.

SOUZA NETO, B. Contribuição e elementos para um metamodelo empreendedor brasileiro: o empreendedorismo de necessidade do "virador". Rio de Janeiro: Blucher Acadêmico, 2008.

STARR, J. A.; MACMILLAN, I. C. Entrepreneurship, resource cooptation, and social contracting. In: ETZIONI, A.; LAWRENCE, P. R. (Org.). Socio-economics: toward a new synthesis. New York: M.E. Sharpe, 1991, p. 167-184

STOREY, D. J. Understanding the small business sector. London: Routledge, 1994. Disponível em: <http://books.google.com.br/books?id=BolPPz5sBV4C\&dq=understanding+the + small+b usiness+sector $\&$ printsec $=$ frontcover $\&$ source $=$ bn $\&$ hl $=$ pt-BR\&ei $=h+6 J S t r I H 4 y y l A e x x J 2 h C w \& s a$ $=X \&$ oi=book_result\&ct=result\&resnum $=4 \# \mathrm{v}=$ onepage\&q=\&f=false $>$. Acesso em: 19 ago. 2009.

UHLANER, L.; THURIK R. Post-materialism: a cultural factor influencing total entrepreneurial activity across nations. Journal of Evolutionary Economics, Zoetermeer, 2007. Disponível em $<$ http://ondernemerschap.panteia.nl/pdf-ez/n200321.pdf>. Acesso em: 22 mai. 2017.

VALE, G. M. V. Laços como ativos territoriais: análise das aglomerações produtivas na perspectiva do capital social. 388 f. Tese (Doutorado em Administração) - Universidade Federal de Lavras, Lavras, 2006.

VALE, G. M. V.; OLIVEIRA, L. de O. Redes sociais na criação e mortalidade de empresas. RAE-Eletrônica, São Paulo, v. 50, n. 3, jul./set. 2010.

VALE, G. M. V.; WILKINSON, J.; AMÂNCIO, R. Empreendedorismo, inovação e redes: uma nova abordagem. RAE-Eletrônica, São Paulo, v. 7, n. 1, jan./jun. 2008.

VASCONCELOS, G. M. R. Empreendedorismo e redes de relacionamento. In: ENCONTRO DA ANPAD, 31., 2007, Rio de Janeiro. Anais... Rio de Janeiro: Windsor Barra Hotel \& Congressos, 2007. p. 1-15.

YIN, R. K. Estudo de caso: planejamento e métodos. 3. ed. Porto Alegre: Bookman, 2007.

Recebido em: 12-12-2016

Aprovado em: 24-04-2017

Avaliado pelo sistema double blind review.

Editor: Elmo Tambosi Filho

Disponível em http://mjs.metodista.br/index.php/roc 